
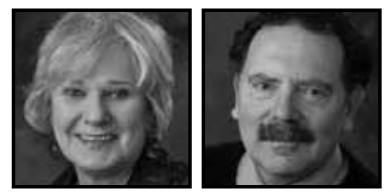

\title{
Commentary
}

\section{How New Research on Learning Is Re-writing How Schools Work and Teachers Teach}

\author{
Renate N. Caine, Natural Learning Research Institute \\ Geoffrey Caine, Caine Learning Center
}

\begin{abstract}
The article introduces the notion of a "meme." A meme is an idea, behavior, or style that spreads from person to person within a culture. In education it acts as a powerful assumption, guiding what is meant by learning and teaching and determines that teaching should include a textbook, teacher-directed lessons, control of student behavior, and testing as proof of "learning." The article explores new challenges to this meme coming from current research emerging out of biology, cognitive psychology, and neuroscience. It suggests that a form of project-based learning is more compatible with how the human brain was designed to make sense of experience.
\end{abstract}

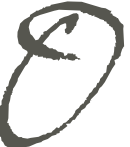

n one of my trips in Canada I was working with a large group of teachers, exploring our Brain/Mind Learning Principles (Caine, Caine, McClintic, \& Klimek, 2009). The purpose of the workshop was to expand everyone's view of the many ways in which human beings learn. At lunchtime I walked around asking particularly new teachers how they felt about the information I was providing. After some hesitation they told me that instead of being excited about how to implement this information when they returned to their classrooms, they were confused and anxious. At the time I felt puzzled. What was happening here?

At the end of the day everyone tried to do his or her best to hide a general sense of frustration. Finally one young teacher stood up and said: "I get it! This makes total sense. You just have to think differently." 
That young teacher was absolutely correct. My presentation was bumping up against deeply held assumptions about the way that schooling and teaching are defined and are generally done. In essence I was asking teachers to move beyond the approach to teaching that everyone believed in. The Brain/Mind Learning Principles called them to go far beyond direct instruction all too frequently required by the system and tied to success on tests.

In our latest book (Caine \& Caine, 2011), we expose this educational paradigm as a "meme." A meme is an organized way of thinking tied to action based on a powerful belief about how the world works, one that is shared by a very large number of individuals. In the case of education it refers to a set of powerful beliefs that are preventing new ideas from taking hold.

For example, let's take the question, "What does it mean to learn in school?" Possibly $90 \%$ of adults who are asked this question will insist that success will require a textbook, prescribed content, and teacher-controlled instruction guided by assignments, homework, and tests. When ninety percent of adults identify these without prompting, we are looking at a "meme." Parents expect to see teacher-assigned homework, grades, and tests; unions want to tie teacher time spent in front of the classroom as equal to "learning" provided and money earned; politicians too look at direct instruction tied to teacher action and ultimately to test scores; all based on beliefs about school and what it means to learn.

Similarly, ask students in any class why they are studying what they are studying and after looking at you as though you are a bit mad, they will respond that they are doing it because their teacher told them to do it or because they have to do it in order to pass a test or get a grade. Their own motivation, enthusiasm, and effort to find unique solutions to personally relevant questions are rarely engaged. (The same incidentally holds true for teachers forced to teach the standards using standardized instruction.) The governing meme keeps everyone from questioning what is being done.

Shifting the meme for education begins with a richer understanding of how human beings learn naturally.

Is brain-based learning and even "neuroeducation" really new? The point is that both could be revolutionary if it were not for the old meme. As it is, powerful research continues to be reduced to what everyone understands schools and schooling to look like. 
This new research reveals a more complex view of what it means to learn, one that includes the role of emotions and higher order thinking. In more recent times, many of these ideas have been either acknowledged or embraced by cognitive psychology and, even more recently, by neuroscience. These developments have revealed much about every aspect of the functioning of a human being, including motivation.

Many educational scholars have been persuaded by the view of so much agreement across disciplines that each person is a unique integrated living system (Fuster, 2003; Damasio, 2005), something that educators have intuitively understood as they experience their students as complex and "whole" individuals every day in their classrooms. The entire organism-the whole person-interacts with its world. When we see that this sophisticated research is documenting that body, brain, heart, and mind are all involved in learning, the real job of the teacher becomes more visible and the call for alternative ways of teaching becomes more justified. The old meme says little about the many social and emotional issues that confront teachers every day.

\section{Perception/Action}

Biologists tell us that every organism (and therefore every one of us) has to develop in two basic and interconnected ways that are indispensable aspects of survival and success - of the continuation of life itself. This is the dance of perception and action-a focus that has been emerging slowly from several different perspectives in recent times (Maturana, Varela, \& Paolucci, 1998; Thompson, 2007; Noe, 2004; Fuster, 2003). From a biological perspective the human brain and body are made to learn by acting on something. We do it every day and it is as natural as breathing. Additionally, neuroscientist Joaquin Fuster (2003) makes clear how the human cortex is developed on the basis of personally relevant questions or challenges that lead to action and feedback.

\section{Where do we see this happening?}

When you see kids working on videogames, you are watching the perception/action cycle in practice. It begins with curiosity about something and a desire to find out more, leads into the need for more information, applying what is being learned, solving a problem and getting feedback. During the cycle they also do a great deal of practice, practice, practice in order to solve small and larger problems and apply solutions that work for them. 
These cycles play out continuously in ordinary, everyday experience. They recur over and over throughout life as people test, and either confirm or change, the ways in which they do things. In a general sense, therefore, "natural learning" can be defined as making sense of experience and acquiring what we have called "performance knowledge" (Caine \& Caine, 2001, 2011). Performance knowledge is a blend of the capacities to perceive and act appropriately in the real world.

\section{Another example from ordinary life}

- Think of the last time you came across a problem that required a decision and action. Let's say that you moved to a new town and decided after settling in to go on a well-deserved vacation but in order to do this you needed to have someone to take care of your pet. This is step one-the problem or dilemma.

- Next you had to formulate a question like, "Who can take care of my dog while I am gone?"This is the second step-the formulation of what E. Goldberg (2001) calls an "actor centered adaptive question." Such questions are personally important and meaningful and contain a challenge.

- Once you formulated a question you had to look up some answers, which is step three-doing some research, finding an expert who knows more than you do. Sometimes experts lead to more questions but ultimately you learn something about who can take care of your pet. Once you find someone you think you can trust, you collect information on availability, additional referrals, and ultimately exchange information with that person and allow him or her to take care of your animal (solve your problem).

- Throughout this process you learn of things you may not have set out to master, such as facts about your neighborhood, who the most helpful neighbors are, where there are other experts available for your pet including a competent vet, food supply store, and so forth.

- Step four is feedback, which happens in an ongoing way as you move through all of these events (in education we call this "formative assessment"). Feedback also happens at the end when you see whether or not your research and your decisions were right-whether in fact you solved your problem (summative assessment).

- What learners come to know in this way cannot only be documented on a test, but it can also be applied in spontaneous ways under multiple circumstances. 


\section{So how does all this translate into education and teaching?}

This view of learning is most compatible with project-based learning and in fact, legitimizes this approach. It also provides direction for experiential learning, constructivism, applied arts, and sports. Any approach to teaching that continually includes:

- Genuine student-generated questions

- The ability to pursue their need to know

- $\quad$ Expansion by linking new experiences and understanding to what learners already know

- An opportunity to create something new

- A challenging learning environment

- Both formative and summative feedback

We (Caine \& Caine, 2011) call our own version of natural learning that relies on perception/action the "Guided Experience Approach." It is more formally presented and aligned with the research I have mentioned in this article. It includes the following steps and requires an environment of what we call "Relaxed Alertness" (Caine, Caine, McClintic, \& Klimek, 2009).

\section{The Guided Experience Approach (GEA)}

1. The GEA begins with a Multisensory Immersive Experience. This is a direct, realworld experience that represents students' preliminary exposure to a new subject or material to be explored.

2. Sensory Processing. This expands awareness of the details and previous experience and triggers greater interest.

Actor-(Student)Centered Adaptive Questions. These are based on authentic student interests and may emerge out of their own lives in some way.

3. Planning, Organizing, and Doing Research and Skill Development.

This begins the real inquiry into the topic. It combines student research, collective and individual inquiry, teacher-led sessions, explanations, and direct instruction on occasion. Skill development is incorporated, as students read, write, research, or pursue deeper understanding and do more processing.

4. Creating a Product That Requires Use of New Learning. This is where new skills and new understanding are applied. At the core is practical application that both enhances accuracy and demonstrates what has been understood and mastered.

5. Formative and Summative Assessments Handled With Ongoing Active Processing. Active Processing is essential and nonnegotiable. 
Throughout the entire process of student-driven learning, the teacher, fellow students, and other experts continually challenge student thinking, expressed assumptions, mastery of concepts, and accuracy.

6. Formal Action and Feedback. Final products are essential to this process. Public demonstrations, presentations, models, or documentations of all kinds take place. Attention is paid to issues ranging from the appropriate use of vocabulary to the ability to answer spontaneous questions ranging from an expert to novice level. Assessment is based on performance and one's ability to verbally explain and present what has been learned using appropriate vocabulary and definitions.

7. Technology. The Guided Experience Approach calls for technology to be infused throughout. Technology can be used at every stage, ranging from accessing research, communication tools and resources, and includes the creation and presentation of final projects.

8. Higher order thinking. Notice also the almost automatic need to include higher order thinking or what is known as executive functions of the human brain. The reason is that in the GEA, there is a need for constant decision making, planning, analyzing, negotiating, and reflecting, both by individuals and collectively (Caine \& Caine, 2011).

\section{So what does all this mean?}

The emerging biological and psychological foundations for learning, grounded in the essentials of perception and action, suggest that great teaching must be geared towards some form of sophisticated project-based learning. The developing understanding of the dance of perception and action further suggests that there are a set of essential elements for good project-based teaching and learning, which we frame in terms of the Guided Experience Approach (Caine \& Caine, 2011). These elements do not need to be sequential but all must be addressed if this more dynamic way of teaching is to include high standards. It seems to us that this view is a powerful umbrella for many, many developments in teaching practices, ranging from self-directed and self-regulated learning to constructivism and service learning. Not everyone will use the same language. But the common patterns will be evident in similar approaches.

This approach to teaching based on natural learning requires many shifts in our collective beliefs about learning, teaching, and "schooling." It will require a fundamental shift in how everyone else sees his or her role and responsibilities. This means that many common understandings tied to the old meme must be unlearned. But 
ultimately, what we propose makes more sense and appears more useful for those who will be living in a connected, information, and collaboration-driven world.

\section{References}

Caine, G., \& Caine, R. N. (2001). The brain, education and the competitive edge. Lanham, MD: Scarecrow Press.

Caine, R. N, \& Caine, G. (2011). Natural learning for a connected world: Education, technology, and the human brain. New York: Teachers College Press.

Caine, R. N., Caine, G., McClintic, C., \& Klimek, K. (2009). $12 \mathrm{brain} / \mathrm{mind}$ learning principles in action: Developing executive functions of the human brain ( $2^{\text {nd }}$ Edition). Thousand Oaks, CA: Corwin Press.

Damasio, A. (2005). Descartes' error: Emotion, reason and the human brain. New York: Penguin.

Fuster, J. M. (2003). Cortex and mind: Unifying cognition. New York: Oxford University Press.
Goldberg, E. (2001). The executive brain: Frontal lobes and the civilized mind. New York: Oxford University Press.

Maturana, H.R., Varela, F. J., \& Paolucci, R. (1998). The tree of knowledge: The biological roots of human understanding. Boston: Shambhala Publications.

Noe, A. (2004). Action in perception. Cambridge, MA: MIT Press.

Thompson, E. (2007). Mind in life: biology, phenomenology, and the science of mind. Boston: Belknap Press of Harvard University Press.

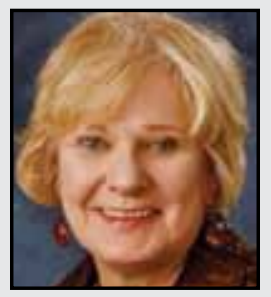

Renate Caine is an education researcher, learning theorist, writer, and consultant. She is the Executive Director of the Natural Learning Research Institute, a 501c3 whose mission is to disseminate research and information on neuroscience and learning. Her work with schools has been featured on "Teacher TV" on the Discovery Channel, "Wizards of Wisdom" on PBS and elsewhere. She is the lead author of a new book published by Teachers College Press (2011) entitled Natural Learning for a Connected World: Education, Technology and the Human Brain. 


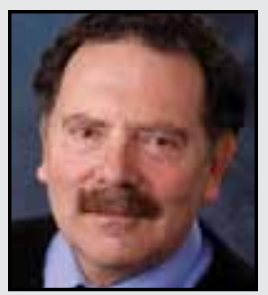

Geoffrey Caine is a Learning Consultant, Writer and Process Coach. He is Co-director of the Caine Learning Center, a professional development organization that serves educators, managers, and others, based on how the brain/mind learns naturally. Geoffrey has co-authored nine books and many chapters and articles on learning and education. He has made many presentations at international, national, and regional conferences. His work carries him throughout the United States and abroad. For instance he was one of the international consultants to Learning to Learn, a leading-edge educational reform program that involved over 200 schools in South Australia.

\section{LINKTO:}

www.naturallearninginstitute.org

www.cainelearning.com 